\title{
Shocks to Brand Equity: An Information Economics Perspective on the US Auto Industry 2006-2011
}

\author{
Joffre Swait • Tulin Erdem • Tom Peters
}

Published online: 29 August 2014

(C) Springer Science+Business Media New York 2014

\begin{abstract}
The US auto industry experienced some turbulent times during the last decade, especially during the 2006-2011 period. The objective of this paper is twofold. First, we want to apply the information economics theoretic framework (e.g., Erdem and Swait (J Consum Psychol 7 (April): 131-157, 1998)) of brand equity and management to assess the impact of the events during this period on consumer brand perceptions and brand consideration in this market. Second, prior information economics theoretic work utilized cross-sectional data (and, further, collected only from student subjects). By collecting two waves of data at widely separated times (2006 and 2011) from consumers who own one or more cars, we are able to test the temporal stability of the information economics framework. Our results indicate that the impact of the various shocks (e.g., bankruptcies, buyouts, product recalls, and the like) on consumer perceptions and behavior during this period can be captured and explained quite well by the information economics theoretic framework: the framework shows remarkable temporal stability. This suggests that tracking key constructs of the framework can lead to reliable forecasts of consumer reactions and serve as the basis for "real-time" brand management, in both crisis and non-crisis modes.
\end{abstract}

Keywords Brand equity $\cdot$ Information economics $\cdot$ Brand credibility $\cdot$ Automotive industry

\author{
J. Swait $(\square)$ \\ Institute for Choice, University of South Australia, Level 13, 140 \\ Arthur Street, North Sydney, NSW 2061, Australia \\ e-mail: Joffre.Swait.Jr@gmail.com \\ T. Erdem \\ The Stern School of Business, New York University, New York, \\ NY 10012, USA \\ T. Peters \\ Deloitte Canada, Toronto, ON, Canada
}

\section{Introduction}

As it neared its centenary mark, the US auto industry was subjected to massive changes during 2006-2011. The three large domestic firms (General Motors, Ford, and Chrysler) were suffering from a long-term decline in sales, lack of innovation and design luster, increased competition from Japanese and Asian brands, and high labor costs, among other problems. For the domestic Big Three, and most particularly GM and Chrysler, history seemed to be leading to an apocalyptic conclusion, as these firms received government bailouts in both the USA and Europe to keep afloat. Ford, however, was able to keep its head above water and manage its way out of its difficulties; during the period it held its own-even more, due to its own efforts as well as changed market conditions, it began to reverse its market share losses.

Meanwhile, the large Japanese auto brands (Toyota and Honda) were able to continue gaining market share as consumer uncertainty with respect to the future of domestic brands caused defections from previously loyal domestic customers. But the generalized worldwide recession took its toll on these firms too, through decreased overall sales. But then Toyota's trial by fire began with a series of sustained product recalls in 2009 and 2010, mainly from issues arising from systematic malfunctions with certain vehicle components in two car models (see the summary of events in Table 4, Appendix 1).

Toyota's difficulties arose chiefly from the subsequent public relations challenges that cropped up in the USA due to Toyota's handling of the situation. Denials, contradictory information, and stonewalling collectively led to a confidence crisis for the Toyota brand in the USA (e.g., [23, 19]). This confidence crisis has turned out to be more serious for the brand than its management no doubt anticipated: purchase consideration of the Toyota brand had plummeted from a high of almost $35 \%$ in 2007/Q2 to a low of approximately $23 \%$ in 
2010/Q4 [6]. This significant $34 \%$ decline in purchase consideration had very concrete and tangible consequences: overall sales, vehicle resale values, brand market share, and perceptions of safety all declined for the brand [7]. The effect was significant enough that the 2009-2010 year-to-year sales for Toyota dropped by $0.4 \%$; to put this statistic into context, Ford, Honda, General Motors (GM), Hyundai, and Nissan all had sales increases of at least $6.9 \%$ in that same period [7].

In this paper, we wish firstly to examine the impact of events such as the bankruptcy and government bailout of GM and Chrysler, the successful crisis management by Ford, and the public relations debacle created by Toyota, on these auto makers' respective brands. We do so through the looking glass of information economics and the brand equity framework of Erdem and Swait [12]. This framework views the brand as a signal to consumers, one which embodies its positioning and history in the marketplace, and is essentially a summary statistic of the brand's willingness and ability to deliver what is promised. According to Erdem and Swait [12], it is the credibility of the brand (specifically, the credibility of the brand as a signal of product positioning) that underlies many of the benefits associated with a strong brand: higher perceived quality, lower price sensitivity, lower decisionmaking costs during choice, lower uncertainty with respect to the post-purchase consumption experience, higher consideration levels, and ultimately, higher likelihood of purchase. In this paper, we investigate how the "shocks" described above, some exogenous (e.g., worldwide recession) and others endogenous (e.g., Toyota's handling of the recalls, GM's inability to garner labor concessions over time to reduce costs), have affected the brand credibility of the major players and consumer brand consideration levels.

Secondly, using two widely separated waves of survey data characterizing changed consumer beliefs due to these multiple "shocks," we study the stability of the information economicsbased brand equity framework ([12] — hereinafter E\&S). Specifically, we base an analysis of the temporal stability of the framework on two panels of US consumers, the first surveyed in November 2006 and the second in February 2011. Prior work on the E\&S framework (e.g., [12, 14, 15, 22]) has been limited to cross-sectional data, so the question of the temporal stability of its premises and hypotheses is open. The changes in the US auto industry during 2006-2011, some of which were cursorily reviewed above, make this an ideal testing platform for such research. The temporal stability of the E\&S framework is also an important question because any model that is considered for forecasting over time must possess this fundamental characteristic. We believe the 51-month gap between the measurements makes for a rather rigorous test of medium- to long-term stability of the framework. We place outside the scope of this paper any testing of the dynamics of brand equity; by the very nature of our data, we are limited to examining issues of model structure and parameter stability at two points in time. Examining the dynamics of brand equity evolution is an exciting future research opportunity. We should also note that all the previous published work that utilized the E\&S framework used data collected from student subjects. Our research is the first application we know of the framework in which data are collected from consumers who own a car (or more) and who are not students.

In subsequent sections, we accomplish the following: we review in more detail the main historical events in which the major brands in the US auto industry were involved during 2006-2011, and in the course of this review, we also introduce the relevant literature on brand equity as a means to lend interpretative clarity to the events from the perspective of the information economics framework of E\&S; next, we describe the data upon which our analyses are based; we then present our major results concerning model structure and parameter stability of the E\&S framework; in sequence, we discuss the implications of our results for the US auto industry in terms of (a) interpreting the five turbulent years 2006-2011 and (b) making recommendations for brand management in shock or crisis situations; finally, we close the paper with a summary of our findings, limitations of our research, and directions for future research.

\section{Literature Review and Conceptual Framework}

There is a very large literature on brand equity in marketing. Aaker [1] defined brand equity as a set of brand assets and liabilities linked to a brand, its name, and symbol, which add to or subtract from the value provided by a product or service to a firm and/or to the firm's customers. Keller [16] offered a cognitive psychology perspective, defining customer-based brand equity as the differential effect that brand knowledge has on consumer response to the marketing of that brand. Adopting an information economics view, Erdem and Swait [12] argue that consumer-based brand equity is the value of a brand as a credible signal of a product's position.

The roles brands play in consumer decision-making, e.g., being the embodiment of certain symbolic or experiential benefits, enhancing quality perceptions, and decreasing risk and information costs (leading to brand equity from the consumers' perspective), may materialize through multiple mechanisms. Some of these are psychological (e.g., associative network memory), some sociological (e.g., brand communities), and others economic (e.g., brands as signals under uncertainty) [17].

Erdem and Swait [12] suggested that brand investments and consistency of the marketing mix and brand positions over time influence the clarity and credibility of brands as signals of product positions. Brands as credible signals of product positions, in turn, increase perceived quality, decrease consumer perceived risk and information costs, and hence 
increase consumer expected utility, as well as brand consideration $[13,22]$. In this framework, the key characteristic of a brand signal is its credibility. Brand credibility (the credibility of a brand as a signal) is defined as the believability of the product position information contained in a brand, which depends on the willingness and ability of firms to deliver what is promised.

Consistency over time has been stressed as one of the pillars of successful brand equity management in various different frameworks of brand equity (e.g., [17, 12]). However, consistency may be difficult to maintain in light of the uncontrolled incidence of exogenous and endogenous shocks: these conspire to make brand equity management over time a challenging task. Indeed, research in marketing on brands in crisis has focused a great deal of attention on product recalls to study the impact of such events on brands. Chen et al. [5] studied the impact of two different strategies, proactive (e.g., voluntary recall in the early stage) vs. passive (e.g., delay recall process or try to shift the responsibilities to other parties) following product recalls in 12 industries. Their event study showed that the stock market responds more negatively to proactive strategies. Another incident that drew academic attention was the peanut butter recall by Kraft in Australia. Van Heerde et al. [21] showed that the product-harm crisis caused (i) a loss in baseline sales, (ii) a reduced own effectiveness for marketing instruments, and (iii) an increased cross sensitivity to rivals' marketing-mix activities. The same peanut butter recall in Australia was studied by Cleeren et al. [4] as well, who found that both pre-crisis loyalty and familiarity with the brand are important buffers against the product-harm crisis, although this resilience decreases over time. Using survey data collected in the field as well as lab studies, Dawar and Pillutla [8] also showed that consumers' existing positive expectations about a brand may provide firms with a form of insurance against the potentially devastating impact of crises.

A number of lab studies have investigated the impact of brand crises (in the form of recalls, negative publicity, and scandals) on brands and brand equity. Roehm and Brady [20] showed that severe failures actually help high-equity brands in the immediate failure aftermath since these failures are accompanied with immediate action; moderate failures, in contrast, work against high-equity brands by presenting relatively few urgent problems to solve and thereby do little to impede brand reevaluation, even at the moment of failure recognition. Ahluwalia et al. [2] study how consumers process negative information about the brands they like and use. Commitment of the consumer toward the brand is identified as a moderator of negative information effects. Specifically, high commitment consumers instinctively counter-argue negative information about that brand.

Overall, these studies suggest that product recalls or negative publicity may hurt sales through various mechanisms (e.g., increased price sensitivity) and brands that command higher loyalty levels from their customer base are in a better position to combat the effects of such crises, especially when they act decisively (even if the short-run effect on stock prices may be negative).

As mentioned in the Introduction, the US auto industry was subject to a series of shocks (e.g., bankruptcies and restructuring, recession, product recalls) between 2006 and 2011 and therefore provides a good opportunity for brand equity researchers to study how such shocks may affect consumer perceptions, brand equity, and consumer behavior (such as brand consideration). The information provided in Tables 3, 4, and 5 (see Appendix 1) show that there were a number of major product recalls during 2005-2011, as well as mergers and buyouts. However, the most striking descriptive information contained therein is the frequency and magnitude of the recalls associated with Toyota, both in the US market and worldwide. Coupled with the problems associated with Toyota's management of these crises [9], and in light of the findings of the literature outlined above on brand crises, these events would lead us to a reasonable expectation that perceived marketing mix consistency, brand credibility, and perceived quality (and consequently brand purchase consideration $^{1}$ ) of Toyota should have dropped between 2006 and 2011, the 2 years in which we collected data. In contrast to Toyota's woes, Ford had increased quality significantly, had very few product recalls, and was seen to handle the recession well without having to file for bankruptcy [10]. We would expect that Ford's brand credibility and brand consideration would increase between our two data collection periods.

In the next section, we describe the data we utilize to understand the impact of such events during the 2006-2010 period on brand credibility and brand consideration, as well as to test the temporal stability of the E\&S framework.

\section{Data Collection and Results}

\subsection{The 2006 and 2011 Cross-Sectional Surveys}

As was indicated earlier, we designed and fielded a survey in November 2006 that sought to characterize the US auto market from the perspective of the E\&S framework. Respondents that were 18 years of age or older and owned at least one economy, sedan, SUV or sports vehicle were drawn from an online commercial panel from across the USA. In broad terms, the survey covered these following areas: (1) characterization of existing and prior automobile holdings at the vehicle brand level; (2) characterization of current vehicle usage and maintenance experience; (3) brand purchase consideration

\footnotetext{
${ }^{1}$ Indeed, as noted earlier, the sales and market shares of Toyota in the USA were negatively affected following these events.
} 
assessments (see Table 6 Appendix 2) ${ }^{2}$; (4) brand perceptions with respect to measurement items relevant to the E\&S framework (brand investments, consistency, clarity, brand credibility, and perceived quality - see Table 6 Appendix 2 for measurement item and scale details); (5) brand performance ratings for functional attributes such as warranty attractiveness, service focus, reliability, relative price, and low operating costs (also see Table 6 Appendix 2); and (6) socio-demographics. Twelve automobile umbrella brands were defined to be of interest: General Motors, Daimler-Chrysler (generally Chrysler herein), Ford, Toyota, Honda, Nissan, Mazda, Hyundai, Kia, Volkswagen, BMW, and Volvo. Respondents were instructed to include specific vehicle brands within the respective umbrella brand when responding to brand-related questions. $^{3}$

In February 2011, 4 years and 3 months after the first data collection, the exact same questionnaire was again fielded using the same online panel and sample selection criteria as in the original survey. In the first wave, 800 completes were obtained, while the second wave had 765 completes. Thus, the two cross-sectional data sets have almost identical levels of statistical reliability.

\subsection{An Overview of Changes from 2006 to 2011}

We first examine aggregate changes between the two waves of data collection, firstly in terms of brand purchase consideration and secondly in terms of the main constructs of the E\&S framework (as well as certain antecedent and successor constructs, e.g., warranty attractiveness). The former results help us to gauge the magnitude of outcome changes that the industry has undergone, while the latter begin to pinpoint possible reasons for these changes. Consideration is a useful measure in this regard because it is a major precursor to actual sales: if a brand is not in the consideration set, it is far less likely to be subsequently purchased.

Figure 1 plots the average likelihood of consideration of the 12 umbrella brands in 2006 and 2011, based on our data. The unit slope line shown in the figure demonstrates that, on average, Ford, Volkswagen, Hyundai, and Kia consideration levels increased over the period, particularly that of Ford, while Toyota, Honda, Nissan, Chrysler, Volvo, and Mazda consideration levels decreased, particularly that of Toyota.

\footnotetext{
${ }^{2}$ Note that the customary brand purchase consideration measures reported for the auto industry are from respondents that are in the market for a vehicle. The brand purchase consideration measure (see Appendix A2) we collected is not limited to in-market respondents, but is based on vehicle owners in general. Thus, our measure is higher than those reported from specialized market research firms.

${ }^{3}$ The specific instructions grouped brands as follows: General Motors (Pontiac, Cadillac, Buick, Chevrolet, and GMC), Ford (Ford and Lincoln), Daimler-Chrysler (Chrysler, Dodge, Mercedes Benz, and Jeep), Toyota (Toyota and Lexus), and Nissan (Nissan and Infiniti). All other brands market their vehicles under their umbrella brand.
}

The GM and BMW brands remained essentially unchanged in terms of this statistic. The consideration level changes of Ford and Toyota are notable in that their changes were quite large: in fact, the proportion of respondents having Ford in their consideration set (defined to be all umbrella brands that the respondent will seriously consider purchasing) increased from $38.0 \%$ in 2006 to $51.9 \%$ in 2011 , which represents a $36.4 \%$ increase; Toyota, in contrast, decreased its presence from 61.1 to $42.2 \%$ of consideration sets, a $30.9 \%$ decrease. This agrees in direction and magnitude of change with CNNMoney [6].

We present a multiple correspondence analysis (MCA) map in Fig. 2 to elucidate changes that occurred in the consideration set structure over time. The map is based on the cooccurrence of brands in respondents' stated umbrella-brand consideration sets. A close proximity of two brands to one another indicates a higher incidence of the two brands in the consideration sets of respondents, while a lesser proximity indicates the converse. The map is based on the structure of 2011 consideration sets, with the 2006 consideration sets being projected into that representation without influencing its structure a priori. Thus, the diagram is useful in depicting the shift of brand positions between the data collection points. The axes of the MCA space are interpretable as follows: the horizontal axis generally distinguishes the domestic brands from all non-domestic brands, while the vertical axis principally distinguishes Asian brands from European brands. Studying the 2011 brand positions at the extremes of the vertical axis, it is possible to interpret the vertical axis as perhaps representing some type of design or engineering innovation difference. This representation of consideration set structure is in accord with expectations about the US market.

According to Fig. 2, the structure of consideration sets has remained quite stable during the interval of interest in terms of the domestic/Asian/European distinction. The MCA map also depicts the changes in brand locations between 2006 and 2011. Largely, relative brand locations have also remained stable across the 4-year period bracketed by the data collection efforts, with one very notable exception: Toyota's location is the only major brand that suffered a downward movement from 2006 to 2011. Given the overall consideration statistics quoted earlier, this downward shift of Toyota in the map is likely to be reflective of its significant consideration losses.

The MCA mapping in Fig. 2 clearly depicts the brand region-of-origin structure of consideration sets in the US auto market. Accordingly, we examined the change in frequency of occurrence of region-of-origin consideration sets (if at least one brand that originates from a region-domestic, Japanese, Korean, European - is considered, then the region is said to be considered) by calculating the degree of change and its statistical significance over the period. Figure 3 shows the z-scores for the mean sample proportions for this level of consideration 
Fig. 1 Average brand consideration levels, US market, 2006 and 2011

sets, of which there are 15 possible. Those consideration sets having $\mathrm{z}$-scores with an absolute value over 1.96 have undergone a significant change (at a $95 \%$ confidence level) in

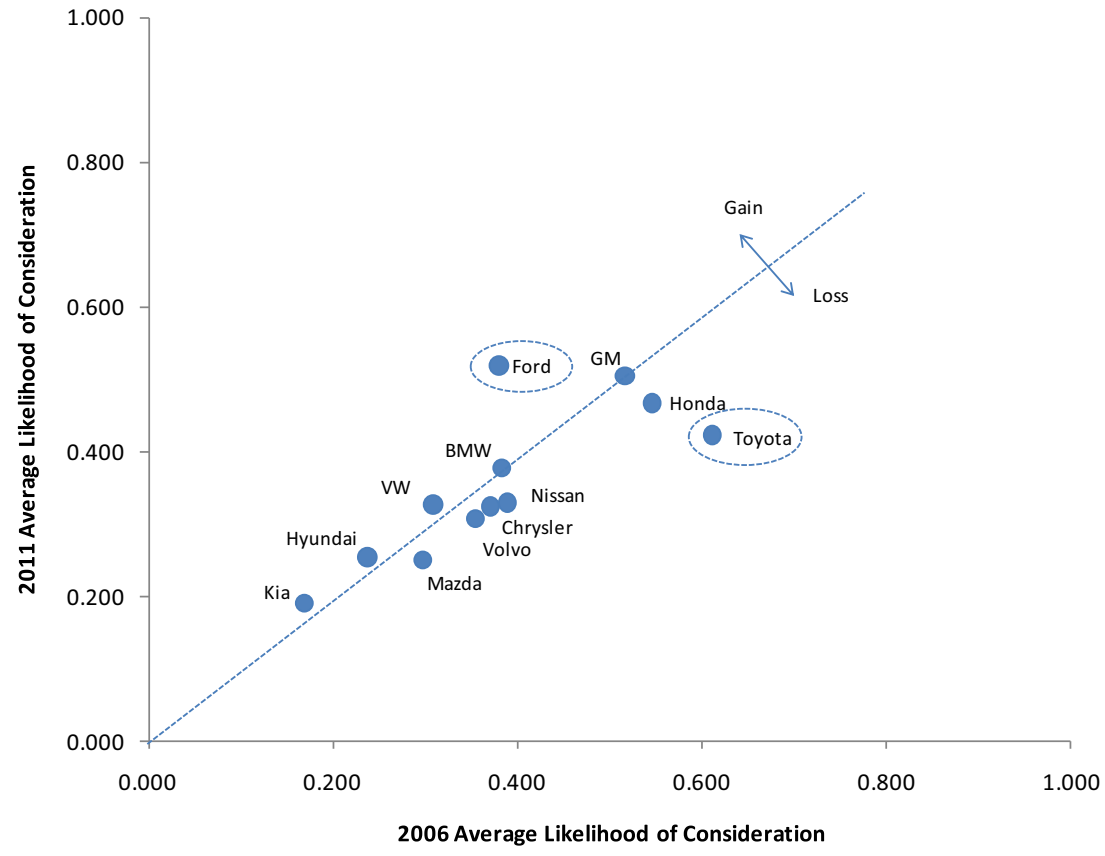

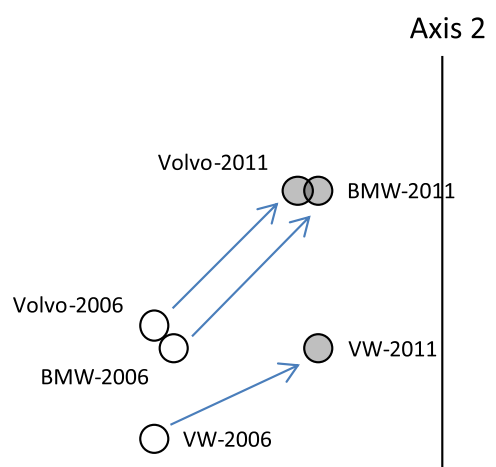

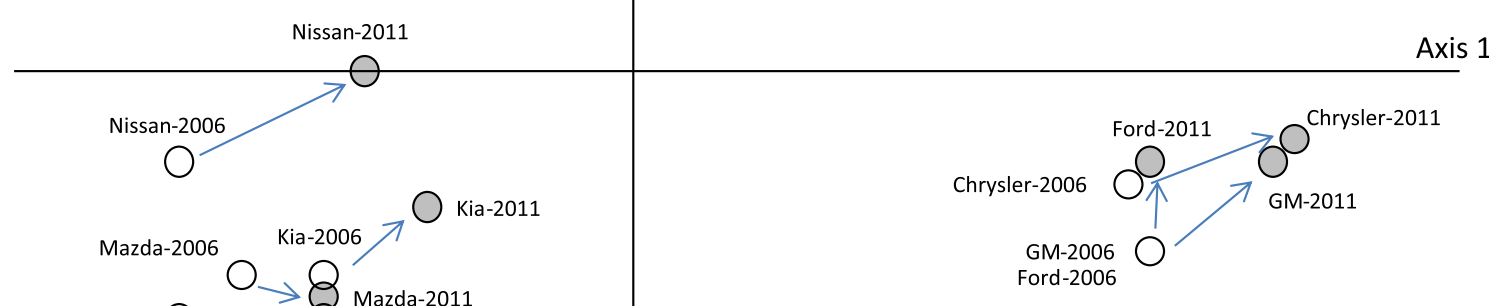

Fig. 2 The 2011 brand consideration set structure map (2006 supplementary) 
isolation and in association with all other regions; conversely, the Korean brands (Hyundai, Kia) have benefited from changes by undergoing an increase in consideration, particularly as a region but also in association with US domestic (GM, Ford, Daimler-Chrysler) and European (BMW, Volvo, Volkswagen) brands. Domestic brands as a group have increased consideration, as they have an association with European brands. Based on Fig. 1, we note that the losses in consideration set incidence centered around Japanese brands is due to impacts mainly on Toyota and secondarily on Honda; for the Korean brands, both have individually improved, while for the Domestic brands, gains are due to the improved performance of the Ford brand.

These different ways of viewing what has occurred in the interval reinforce the message that the brand-related events from 2006 to 2011 may have had serious consequences for certain brands, both major and minor (i.e., negatively for Toyota and Honda and positively for Ford, Hyundai, and Kia). But what might be some of the mechanisms for this change in the consideration of brands? We examine this question at two levels: first, we look at functional attributes, such as service focus, warranty attractiveness, reliability, low operating costs, relative price, and purchase consideration, to attempt a diagnosis for the decrease in the latter construct; second, we look more deeply at what happened to the brands from an information economics perspective. In the presentation that follows, the aforementioned constructs are operationally defined as specified in Appendix 2, to which the reader is directed for details.

Figure 4 shows the z-scores for the mean construct levels for the five major brands of the US market: Ford, GM, Daimler-Chrysler, Toyota, and Honda. A positive score indicates that the mean increased over the 2006 to 2011 period, and its magnitude over 1.96 indicates that the difference is statistically significant at the $95 \%$ level. As a whole, there are three major observations to be made from this graph. Firstly, in a time of worldwide recession, it is notable to observe that the changes in brand consideration across all brands are seemingly unrelated to changes in relative price perceptions, which remained essentially stable across the period. Secondly, for Ford and Toyota, all other constructs changed significantly: for the former brand, perceptions of service orientation, warranty quality, vehicle reliability, and low operating costs improved significantly, whereas the opposite occurred for Toyota. Thirdly, for the remaining brands, some constructs improved or degraded somewhat, but nothing major seems to have occurred. Arguably, this figure shows a strong halo effect across all the constructs for Ford and Toyota: the former is seen as improved across the board, while Toyota is more negatively perceived across the board.

However, if we look a little closer under the hood, we find that what may seem merely a halo effect surrounding the good or bad fortunes of a brand may have a more rational basis than suggested by analyses presented thus far. To take a deeper look at what may have occurred, we first present Fig. 5 to remind the reader of the general structural relationships contained in the information economics framework of Erdem and Swait [12]. The brand is seen to function as a signal for the consumer, its major property being the credibility to consumers of the positioning claims made by the brand. This credibility is a function of brand investments (e.g., advertising levels, sponsorships), consistency in the marketing mix across elements (e.g., price and quality consistency) and over time (e.g., quality stability, advertising consistency), and clarity of brand messages. In turn, the credibility of the brand affects quality perceptions and reduces decision-making costs (via reductions in perceived risk and information cost savings). These impact the utility [12] and consideration [15] of the brand.

The constructs of the E\&S framework are arrayed in a leftto-right order in Fig. 6 in a manner consistent with the framework in Fig. $5 .{ }^{4}$ Focusing our discussion on the Toyota and Ford brands, it is clear that the former suffered a dramatic decline in quality perceptions from 2006 to 2011, while the latter benefited from a great improvement in perceived quality levels. This is generally consistent with the message of Fig. 4. However, Fig. 6 enables us to go back up the chain to pinpoint the heart of the issue for both these brands as being the consistency construct. Aligning Figs. 5 and 6 allows us to tag an increase in consistency as the reason for Ford's significant improvement and Toyota's significant degradation in consideration levels. In addition, improvement (worsening) in the clarity construct for Ford (Toyota) adds to the significant upward (downward) shift in the core construct of brand credibility. Finally, note that perceptions of the brand investments construct do not significantly change in the period, allowing us to suggest that changes in brand credibility (and ultimately to consideration) arise due to changes in consistency.

Thus, at the heart of Toyota's problems in consideration levels is the issue of the credibility of its claims about its products in the face of a series of product recalls and the brand's handling of these product recalls, which seem to have negatively affected consumer perceptions of consistency,

\footnotetext{
${ }^{4}$ Please note that the only construct that is present in the E\&S framework (Fig. 5) and is not included in our analysis (Fig. 6) is "decision costs benefits" (e.g., decreased consumer perceived risk and information costs due to brand as a signal). The original intent of the 2006 survey was the testing of a concise version of the E\&S for the purposes of formulating an instrument to track the key construct brand credibility over time. Pretesting of the instrument showed that response rates decreased significantly with the inclusion of the entire framework in the survey, so the perceived risk and information costs constructs were excluded from the fielded version to increase response rates by reducing respondent cognitive burden. The effect of these mediating constructs is still captured, however, via the direct link from brand credibility to consideration in Fig. 5.
} 
Fig. 3 Changes in region-oforigin consideration sets

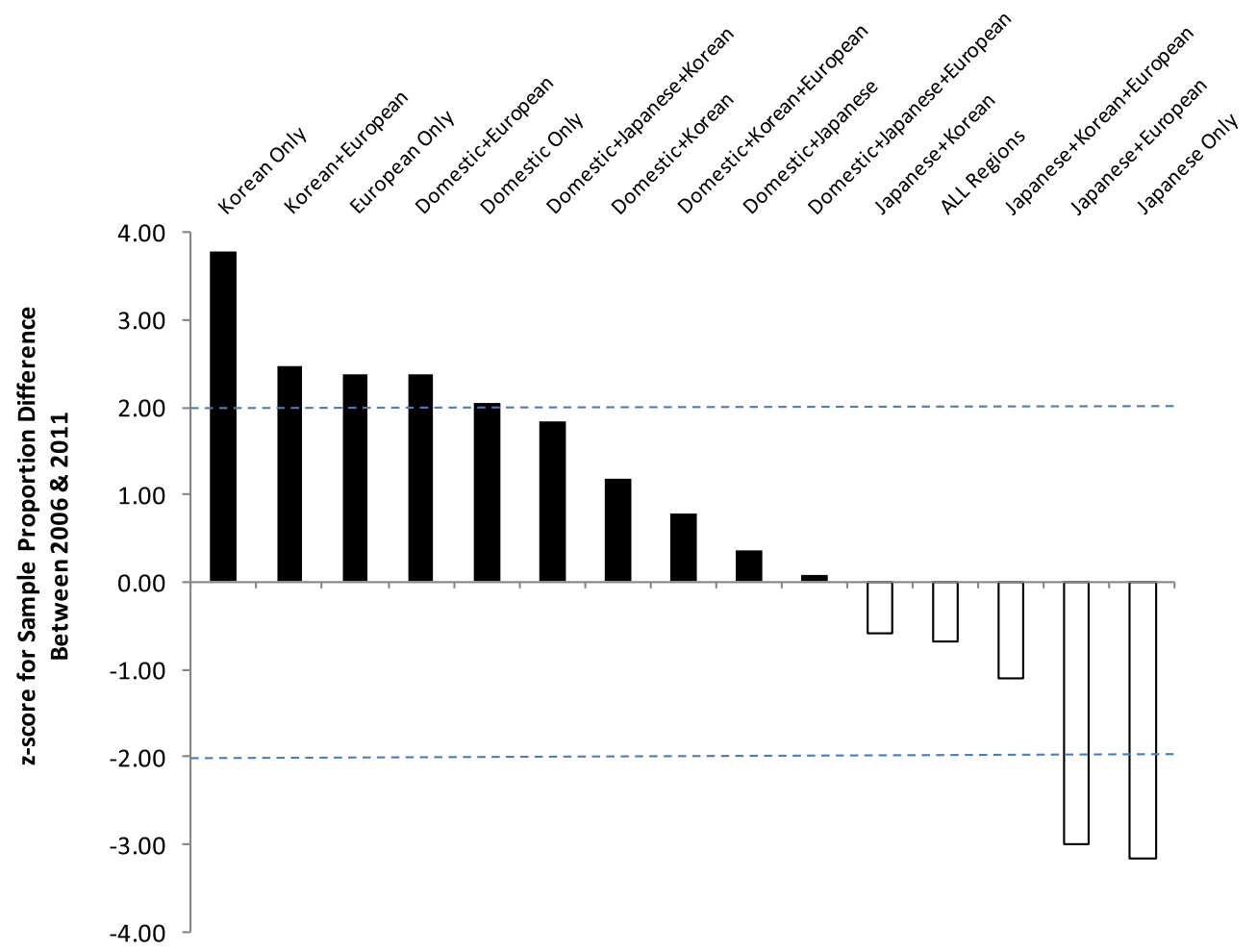

Brand Region-of-Origin Consideration Set

perceived quality, brand credibility and, hence, brand consideration. On the other hand, Ford managed to improve its perceived quality (see also Economist [10], which indicates that the brand was already on a quality improvement gradient before the period we are examining), brand credibility, and consideration. These results are consistent with news reports such as the following: “...the troubled Japanese automaker will probably see its market share drop to its lowest level in
Fig. 4 Change in automobile evaluation constructs from 2006 to 2011, US auto market

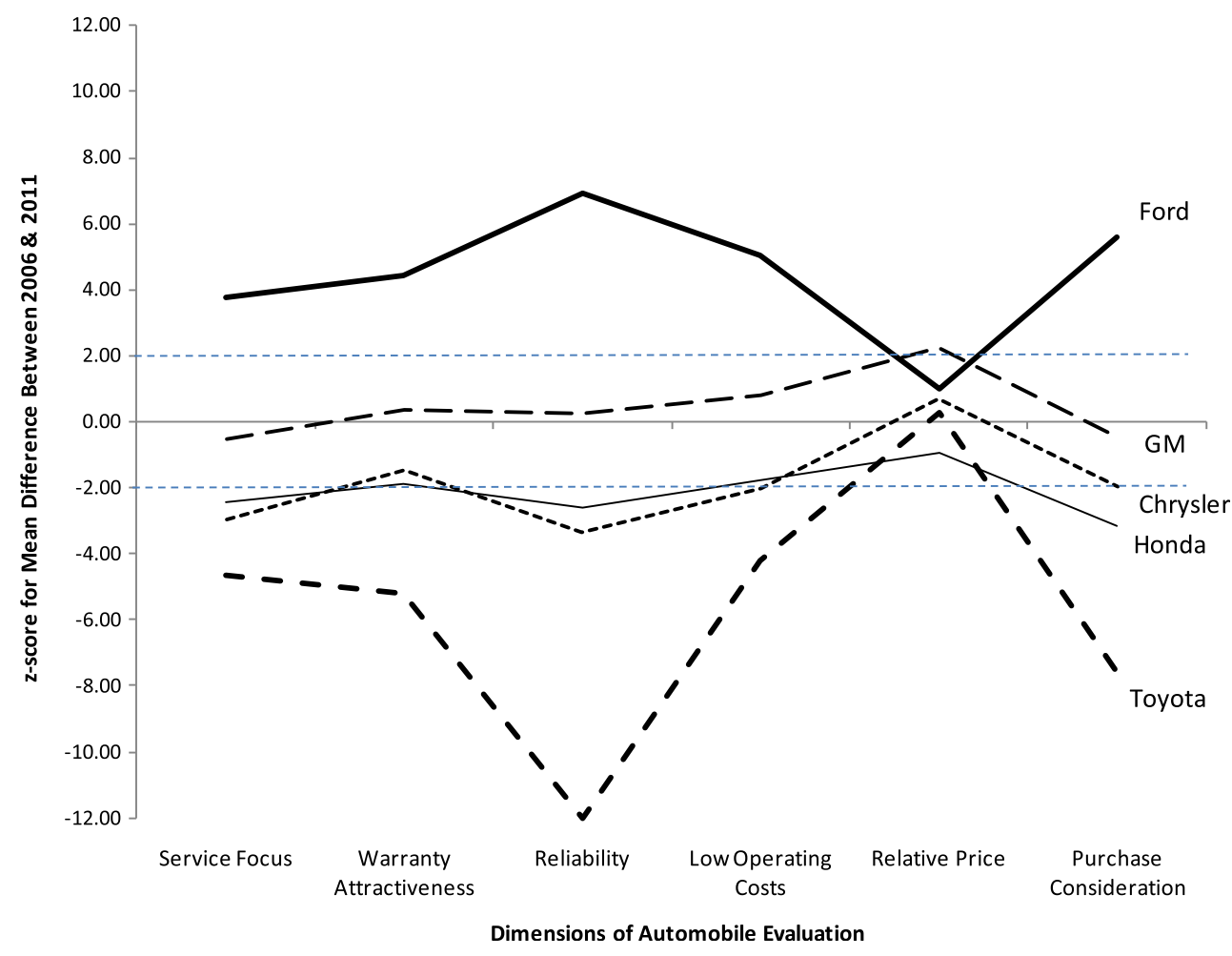




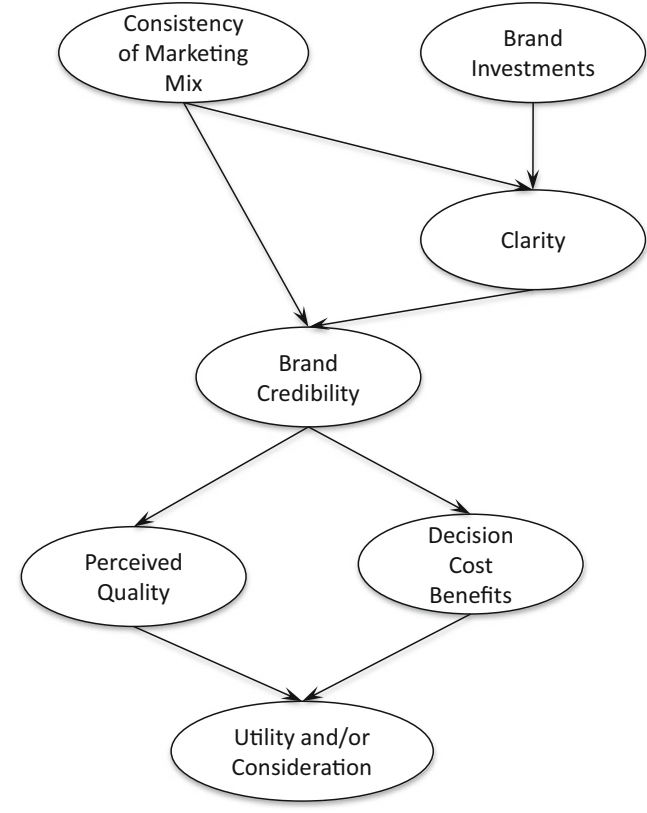

Fig. 5 Erdem and Swait [12] framework schematic

almost five years, giving the runner-up spot in the U.S. back to Ford Motor Co.” [18]

\subsection{The Stability of Brand Consideration}

In this section, we briefly analyze the temporal stability of brand consideration. We are motivated by the observations above to ask whether the relationship between brand credibility and the key outcome (brand) purchase consideration has changed during the 4-year interval in terms of its underlying drivers. Accordingly, we estimated a pooled binary logistic consideration model over the two waves of data, regressing this dependent variable on brand constants, reliability (Rel), low operating costs (LOC), relative price (RP), brand credibility (BCr), perceived quality (PQ), and prior ownership of the brand. We included brand credibility as an explanatory variable since it affects consideration not just through perceived quality but through other constructs (see Fig. 5), including constructs such as decision cost benefits (e.g., decreased information costs) that we have not measured directly. Reliability, low operating costs, and relative price are included as functional attributes. ${ }^{5} \mathrm{We}$ also include wave interactions

\footnotetext{
$\overline{5}$ Service focus and warranty attractiveness, two additional functional attributes we collected data on, are not included in this analysis since their inclusion leads to counterintuitive signs for them. This arises due to multicollinearity between these constructs and the others included in the final binary logistic consideration model. Note that this problem does not arise when we estimate the simultaneous equation system (SES) models presented next, since SES captures the structural relationships. The binary logistic model presented here is a reduced form representation and does not reflect these structural relationships.
}

to test for possible differences. This model is presented in Table 1: it demonstrates a very respectable goodnessof-fit (McFadden's rho-squared is 0.423) and has all parameter estimates in expected directions.

The most important variables in explaining consideration are $\mathrm{BCr}$ and $\mathrm{PQ}$, the former a particularly key construct in the E\&S framework (see Fig. 5); both these constructs increase consideration, consistent with prior research on consideration (Erdem and Swait 2004). The next most important impact on consideration is the influence of prior ownership experience with a brand (brand owned before- $\mathrm{BrOwnB}$ ): such experience considerably enhances the likelihood of brand consideration. In addition, RP and LOC are found to be statistically significant in accounting for increases in consideration. Finally, there are some significant brand-specific constants that capture, on average, differences between the 12 focal brands of our study.

Of most substantive interest to us, however, are the differential driver impacts on consideration likelihood between the 2 years. Accordingly, we included interactions of year/wave with the intercept, brand constants, the constructs mentioned above, and prior ownership. The model in Table 1 indicates that the consideration model is essentially the same across the waves, with a small but statistically significant decrease in the impact of $\mathrm{BCr}$ and an increase in the impact of PQ. These two effects may point to a small decrease in the role of $\mathrm{BCr}$ in 2011 compared to 2006, with a concomitant increase in the role of PQ across the two points in time.

These observations concerning (a) the stability of brand consideration across the years and (b) the maintained stability of the relationship between consideration and key constructs of the E\&S framework suggest that there are predictable underlying reasons for the changes observed in consideration across the two time points. In turn, this observation raises the question of whether the E\&S framework itself (see Fig. 5) is stable over time. We broach this topic in the next section.

\subsection{The Temporal Stability of the E\&S Framework}

In this section, we present several simultaneous equation system (SES) models of the E\&S framework, extended to include the functional (perceived) attributes mentioned above and defined specifically in Appendix 2. We present wavespecific models then test for the stability of all coefficients across the waves.

First, however, we discuss the rationale for the addition of antecedent and successor constructs to the basic E\&S framework, previously presented in Fig. 5. The extended model system is shown in Figs. 7 and 8, respectively, presenting the estimated standardized path coefficients for the 2006 and 2011 waves of data collection. The additional constructs are warranty attractiveness, service focus, reliability, relative 
Fig. 6 Change in information economics constructs from 2006 to 2011, US auto market

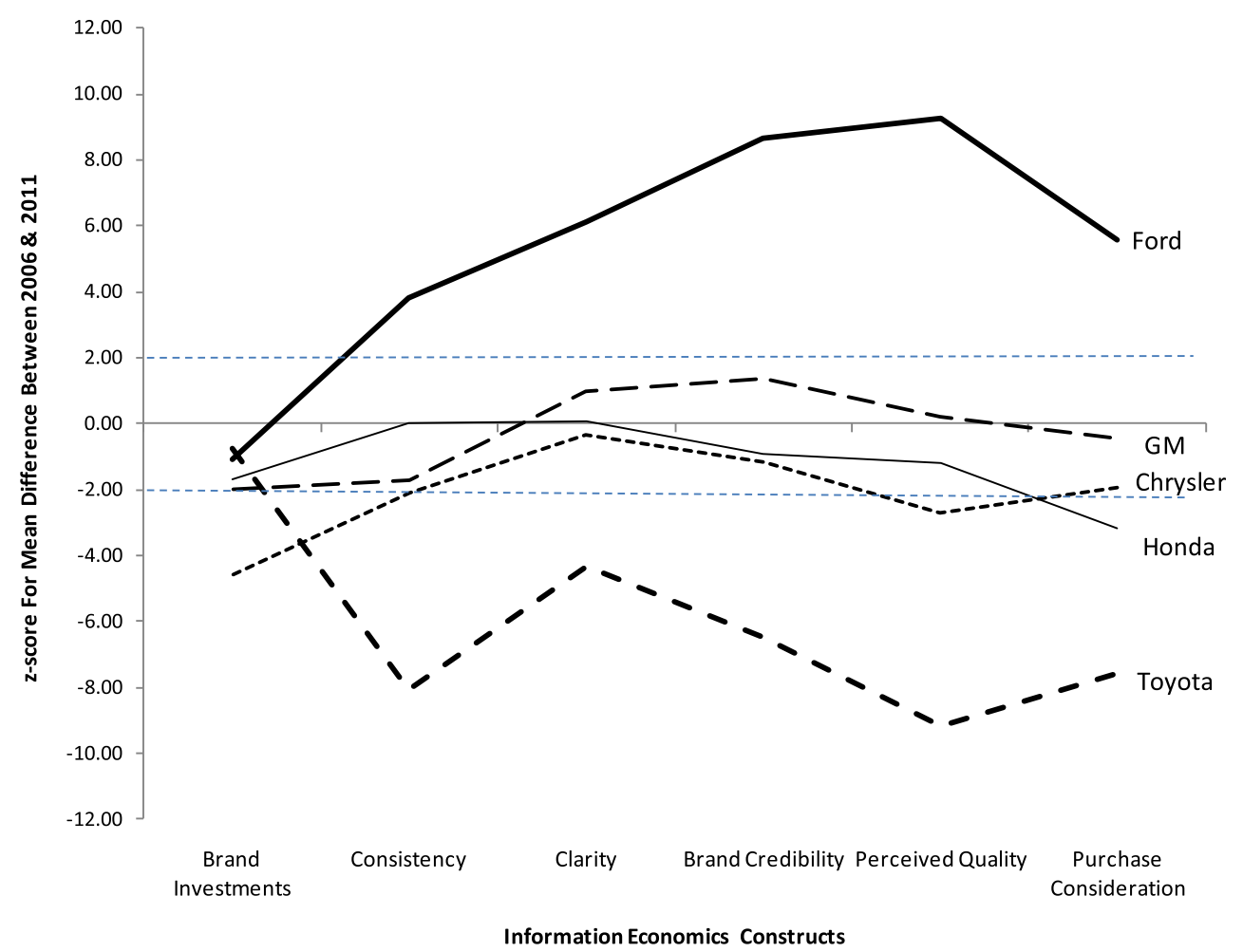

price, and low operating costs. These attributes were identified as the most relevant functional product attributes in car purchases in pre-tests. We also collected data on the brand previously owned which is included throughout the simultaneous equation systems in Figs. 7 and 8 to capture state dependence effects. Finally, as previously mentioned, we did not collect data on decision benefits (information costs and perceived risk), so although Fig. 5 notes this construct to show the E\&S framework, the SES models estimated do not incorporate the decision costs benefits directly, but link the brand credibility construct directly to brand consideration as a reduced form representation of the full original framework.

The SESs for the two waves exhibit quite high goodnessof-fit, as can be seen in Table 2. With over 9,000 observations per model, and the fact that the chi-squared statistics are only $164.9(\mathrm{DF}=19)$ and $224.7(\mathrm{DF}=19)$ for 2006 and 2011, respectively, supports this conclusion. (The over-sensitivity of the chi-squared statistic in large samples is well known; see [3].) The adjusted GFIs of the two wave-specific models are over 0.97, NFIs are greater than 0.98, RMRs are less than 0.003 , and RMSEAs less than 0.035 for both models. In addition, examination of the $R^{2} \mathrm{~s}$ of individual equations in the systems (see Table 2 also) in both years shows that most of them (and particularly the core constructs of the E\&S framework) have very reasonable, if not excellent, goodness-of-fit statistics. Signs of all path coefficients are as expected, again in both years. An inspection of the path coefficients across the two diagrams will show that even the magnitudes of individual path coefficients are very similar, which leads us to wonder whether a joint model might adequately describe the observed measures across time.

Accordingly, we present in Table 2 the goodness-of-fit measures for the joint SES. Because a formal hypothesis test based on differences in chi-squared is overly sensitive in large samples (almost 19,000 observations), it is better to gauge the performance of the joint model using other fit measures. Notably, the joint model (1) has path and other parameters (variances and covariances) that are very similar to those of the year-specific models; (2) displays very good overall GFI, NFI, RMR, and RMSEA measures (comparable to the yearspecific models); and (3) goodness-of-fit statistics for individual equations are also very similar to those of the individual years (see Table 2). Practically speaking, this result points to the stability of the E\&S framework across the 4-year period.

The substantive implication of this empirical determination of framework stability is principally that the partial attribution of brand consideration level changes over the period to changes in brand credibility is quite believable and highly reliable. While other factors might also influence a decline (e.g., reduction in the number of dealerships by a brand might create a perception that it has become more difficult to buy the brand) or an increase in consideration (e.g., difficulties experienced by one brand might create a relative advantage for another brand), the stability of the E\&S framework allows us to parse out the impacts of these brand 
Table 1 Binary logistic brand consideration model

\begin{tabular}{|c|c|c|c|c|}
\hline & Variables & Estimated parameter & Asymptotic t-stat & $p$ value \\
\hline \multirow{31}{*}{$\begin{array}{l}\text { Average Effects over } \\
2006 \text { and } 2011\end{array}$} & Intercept & -2.283 & -63.53 & $<.0001^{* *}$ \\
\hline & GM & 0.671 & 6.45 & $<.0001^{* *}$ \\
\hline & Ford & 0.418 & 4.36 & $<.0001 * *$ \\
\hline & Chrysler & 0.082 & 0.95 & 0.3433 \\
\hline & Toyota & 0.254 & 3.23 & $0.0012 * *$ \\
\hline & Honda & 0.184 & 2.59 & $0.0097 * *$ \\
\hline & Mazda & -0.071 & -0.96 & 0.3365 \\
\hline & Hyundai & 0.048 & 0.61 & 0.5391 \\
\hline & $\mathrm{Kia}$ & -0.041 & -0.49 & 0.6274 \\
\hline & BMW & -0.707 & -10.18 & $<.0001 * *$ \\
\hline & Volvo & -0.715 & -10.25 & $<.0001^{* *}$ \\
\hline & Volkswagen & -0.238 & -3.31 & $0.0009^{* *}$ \\
\hline & Nissan & $0.115^{\mathrm{a}}$ & - & - \\
\hline & Reliability & 0.231 & 5.05 & $<.0001^{* *}$ \\
\hline & Low operating costs & 0.135 & 3.70 & $0.0002 * *$ \\
\hline & Relative price & 0.013 & 0.39 & 0.6995 \\
\hline & Brand Credibility & 1.085 & 29.78 & $<.0001^{* *}$ \\
\hline & Perceived quality & 1.593 & 26.32 & $<.0001 * *$ \\
\hline & Brand owned before (BrOwnB) & 1.259 & 15.55 & $<.0001^{* *}$ \\
\hline & BrOwnB $\times \mathrm{GM}$ & -0.260 & -1.66 & $0.0960^{*}$ \\
\hline & BrOwnB $\times$ Ford & -0.142 & -0.91 & 0.3605 \\
\hline & BrOwnB $\times$ Chrysler & -0.354 & -2.24 & $0.0252 * *$ \\
\hline & BrOwnB $\times$ Toyota & -0.070 & -0.39 & 0.6968 \\
\hline & BrOwnB $\times$ Honda & 0.290 & 1.35 & 0.1784 \\
\hline & BrOwnB $\times$ Mazda & 0.019 & 0.07 & 0.9432 \\
\hline & BrOwnB $\times$ Hyundai & -0.073 & -0.29 & 0.7744 \\
\hline & $\mathrm{BrOwnB} \times \mathrm{Kia}$ & 0.895 & 2.19 & $0.0286^{* *}$ \\
\hline & BrOwnB $\times$ BMW & 0.037 & 0.10 & 0.9207 \\
\hline & BrOwnB $\times$ Volvo & -0.193 & -0.45 & 0.6503 \\
\hline & BrOwnB $\times$ Volkswagen & -0.389 & -1.71 & $0.0864^{*}$ \\
\hline & BrOwnB $\times$ Nissan & $0.238^{\mathrm{a}}$ & - & - \\
\hline \multirow[t]{18}{*}{2011 vs 2006} & Year $(1=2011 /-1=2006)$ & -0.060 & -1.68 & $0.0937^{*}$ \\
\hline & GM×year & 0.109 & 1.47 & 0.1410 \\
\hline & Ford $\times$ year & 0.111 & 1.53 & 0.1266 \\
\hline & Chrysler $\times$ year & 0.010 & 0.15 & 0.8839 \\
\hline & Toyota $\times$ year & -0.162 & -2.32 & $0.0202 * *$ \\
\hline & Honda $\times$ year & -0.134 & -2.01 & $0.0441 * *$ \\
\hline & Mazda $\times$ year & -0.026 & -0.38 & 0.7063 \\
\hline & Hyundai $\times$ year & 0.103 & 1.38 & 0.1671 \\
\hline & Kia $\times$ year & 0.128 & 1.55 & $0.1221^{*}$ \\
\hline & BMW×year & -0.057 & -0.83 & 0.4065 \\
\hline & Volvo $\times$ year & -0.034 & -0.49 & 0.6266 \\
\hline & Volkswagen $\times$ year & 0.051 & 0.75 & 0.4540 \\
\hline & Nissan $\times$ year & $-0.098^{\mathrm{a}}$ & - & - \\
\hline & Reliability $\times$ year & -0.075 & -1.65 & $0.0997 *$ \\
\hline & Low operating costs $\times$ year & 0.023 & 0.64 & 0.5247 \\
\hline & Relative price $\times$ year & 0.051 & 1.49 & 0.1360 \\
\hline & Brand credibility $\times$ year & -0.107 & -2.94 & $0.0033^{* *}$ \\
\hline & Perceived quality $\times$ year & 0.136 & 2.24 & $0.0249 * *$ \\
\hline
\end{tabular}


Table 1 (continued)

\begin{tabular}{lll}
\hline Variables & Estimated parameter & Asymptotic t-stat \\
\hline Brand owned before $\times$ year & -0.021 & -0.34 \\
LL (Conv) & $-7,511.08$ & 0.7301 \\
LL (0) & $-13,017.3$ \\
McFadden's $\rho^{2}$ & 0.4230 \\
Number of observations & 18,780 \\
\hline
\end{tabular}

*Significant at $90 \%$ level; ** significant at $95 \%$ or higher level

${ }^{a}$ Not estimated, calculated from effects coding of Nissan brand

crises on a major precursor to sales, to wit, brand consideration. The stability also implies that the E\&S framework can serve as the basis for a tracking and forecasting component in a brand management decision support system. At a minimum, the knowledge that the structural relationships embodied in Figs. 5, 7, and 8 are stable can help brand managers to generate options in nascent brand crises and gauge market responses to their actions.

\section{Discussion, Summary, and Conclusions}

Adopting an information economics view and utilizing the data we collected in two waves (2006 and 2011), we studied the change in consumer perceptions and brand consideration in the auto industry in the USA over a 4-year period. Our results indicate that constructs such as consistency of the marketing mix and over time, brand credibility, and perceived
Fig. 7 Simultaneous equation system, E\&S framework-2006 US auto market

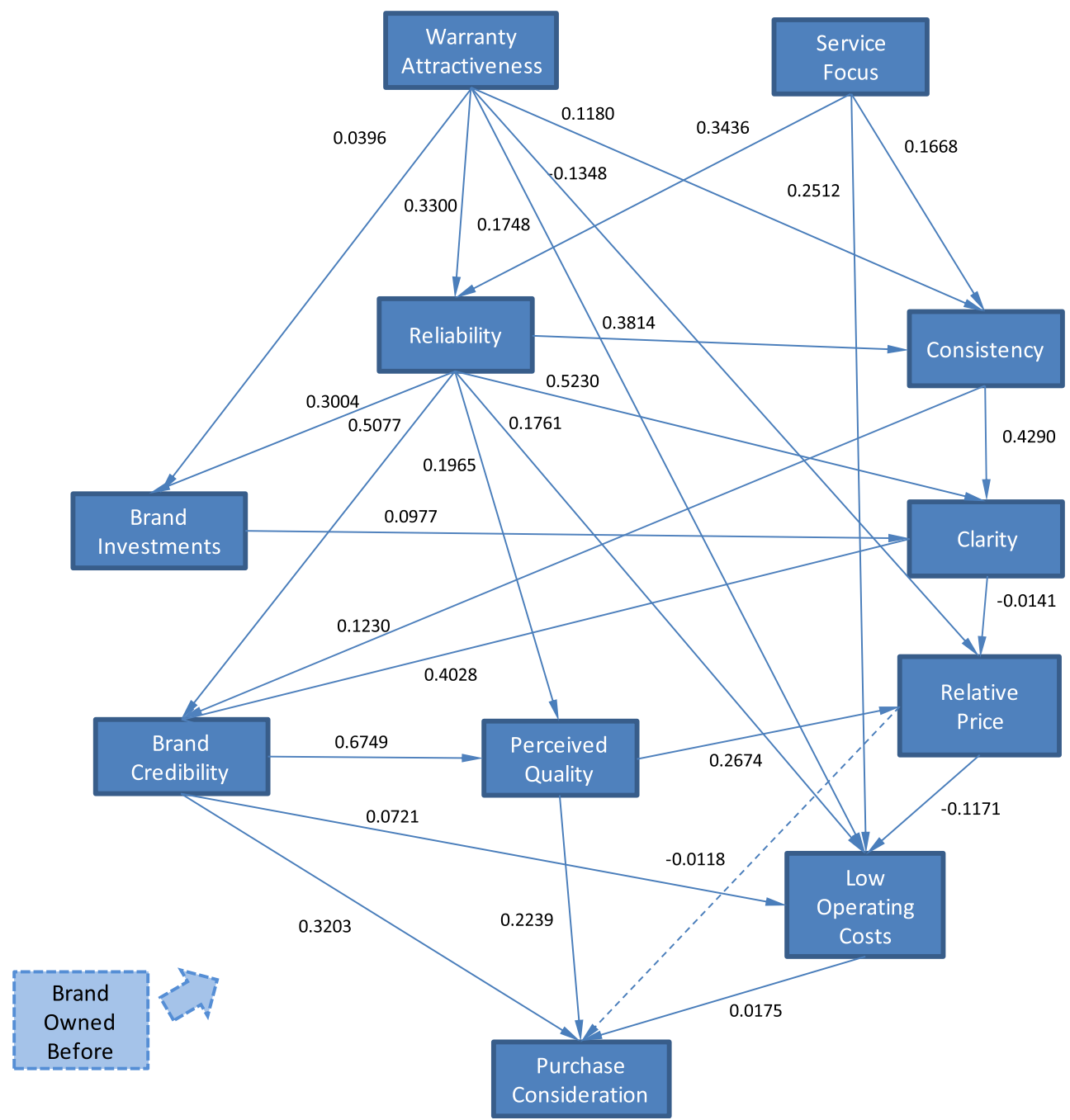


Fig. 8 Simultaneous equation system, E\&S framework-2011 US auto market

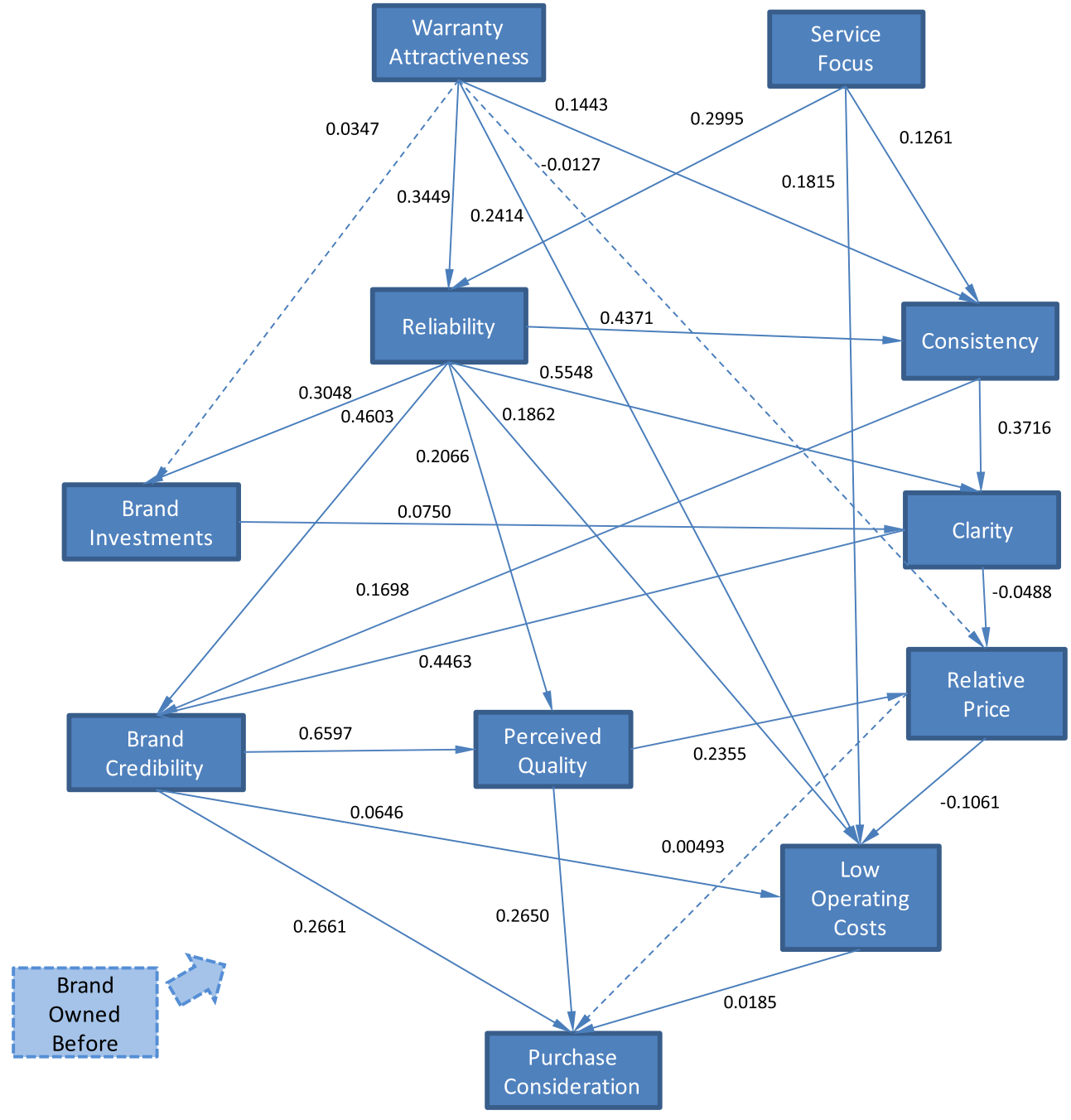

quality underlie consumer brand consideration and explain consumer attitudes towards brands in the wake of various "shocks" (e.g., bankruptcies, product recalls).

Our examination of the US auto market from the information economics perspective has allowed insights into the more likely reasons for certain changes that occurred in that market from 2006 to 2011. Somewhat surprisingly, the financial crises (i.e., bankruptcies, government bailouts) of players like GM and Chrysler does not seem to have had the highly deleterious brandrelated effects that no doubt many expected and predicted for them. These still-major domestic brands held their own in a turbulent environment. Ford, already on an improvement gradient when the financial difficulties began for the sector [10], may have been the greatest beneficiary of the changes in the US market. But these gains for Ford have not come through simple improvement of a relative positioning vis-à-vis other brands: rather, in consonance with the information economics framework [12], its standing improved through detectable changes in brand credibility, which ultimately led to highly significant changes in purchase consideration, which then led to more than proportional increases in sales (Appendix 1 Table 3).

After Ford, the second "winner" in the evolving market coming out of the 2006-2011 period was the Kia brand. While a relatively minor player in the market, accounting for about $3.7 \%$ of sales in 2010 among the 12 brands we studied, our data indicate that this brand had a $98 \%$ increase in brand credibility perceptions between 2006 and 2011. This accounted for a $12.3 \%$ increase in consideration for Kia in the period. Thus, its gains in sales cannot be simply attributed to improved relative position; instead, consumers were increasingly attributing greater trustworthiness to its claims, which in turn led to improved consideration, which converted into more sales.

Toyota, while the leader in sales at the end of the period, is the brand that took a serious drubbing at the hands of the market. As our data indicate, its purchase consideration 
Table 2 Simultaneous equation system goodness-of-fit statistics

\begin{tabular}{llll}
\hline Goodness-of-fit & 2006 & 2011 & Joint \\
\hline Chi-squared (DF) & $164.58(19)$ & $224.75(19)$ & $315.56(19)$ \\
GFI adjusted for DF & 0.977 & 0.968 & 0.978 \\
NFI [3] & 0.992 & 0.987 & 0.991 \\
Root mean residual (RMR) & 0.0021 & 0.0027 & 0.0021 \\
RMSEA & 0.0283 & 0.0343 & 0.0288 \\
Number of observations & 9,600 & 9,180 & 18,780 \\
$R^{2}$ by equation & & & \\
Warranty attractiveness & 0.239 & 0.195 & 0.214 \\
Reliability & 0.587 & 0.507 & 0.542 \\
Service focus & 0.195 & 0.135 & 0.162 \\
Brand investments & 0.225 & 0.150 & 0.178 \\
Clarity & 0.572 & 0.588 & 0.579 \\
Consistency & 0.558 & 0.574 & 0.563 \\
Brand credibility & 0.701 & 0.717 & 0.707 \\
Perceived quality & 0.746 & 0.733 & 0.739 \\
Consideration & 0.642 & 0.610 & 0.625 \\
Low operating costs & 0.370 & 0.355 & 0.360 \\
Relative price & 0.234 & 0.226 & 0.227 \\
\hline
\end{tabular}

declined $31 \%$ in the 51 months after November 2006. Viewed from the perspective of the Erdem and Swait [12] framework, the basic reason for this large loss in consideration is due to a decrease in consistency of the marketing mix, specifically as relates to its impact on the credibility of the claims made by the Toyota brand. Aligning this insight with the behavior of the company in the face of recalls both in the USA and elsewhere makes it patent that the brand crisis arose due to the mishandling of the recall: slowness of response, denials, prevarication, and so forth. These led to the perception by consumers that the brand was reneging on its promises relating to product quality and other dimensions of evaluation, i.e., the brand was being inconsistent with respect to its prior claims and consumers' expectations (Appendix 1 Table 4).

Toyota's experience with the public relations difficulties created during 2010 with the various product recalls is not simply a cautionary tale for brand managers. It also raises the question about the preventability of such consequences: would the existence of hard data on the possible consequences of taking certain brand-level actions have deterred Toyota executives from taking the road they traveled? While answering that particular question is beyond the scope of our paper, our results suggest that at a minimum the tracking of constructs from the information economics framework (see Fig. 5) would have been a useful source of information to support management decision-making before, during, and after the recalls. Establishing the temporal stability of the
E\&S framework, as we have succeeded in doing, makes it possible to assert the usefulness of using this theory as a basis for guiding managerial action (Appendix 1, Table 5).

This research attempted the first assessment of the face validity and temporal stability of the information economic theoretic framework of brand equity proposed by Erdem and Swait [12] by using "field data" (Appendix 2, Table 6). However, to explicitly capture the dynamics of brand equity management over time, one needs to utilize panel data with multiple observations over time for each panelist. While there is work utilizing scanner panel data on topics such as how price promotions may erode brand equity over time (e.g., [11]), applying brand equity frameworks to dynamic contexts (e.g., estimating the evolution of the brand equity components, e.g., the impact of consistency over time) remains a future research issue that is in definite need of exploration.

\section{Appendix 1-Major Events (2005-2010) in the US Auto Industry}

Table 3 The 2005-2010 major global auto recalls in the USA (except Toyota)

$\begin{array}{cl}\text { April 2005 } & \text { GM said it was recalling more than } 2 \text { million vehicles } \\ & \text { to fix a variety of potential safety defects, most } \\ \text { of them on cars and trucks sold in the USA. GM } \\ \text { said the largest of the safety actions included } \\ 1.5 \text { million full-size pickup trucks and sport utility } \\ \text { vehicles from the } 2003 \text { to } 2005 \text { model years with } \\ \text { second-row seat belts that may be difficult to } \\ \text { properly position across the passengers' hips } \\ \text { [For pickups and vans] Chrysler LLC said it would } \\ \text { recall 575,417 vehicles as long-term wear on } \\ \text { the gear shift assembly could cause them to shift } \\ \text { out of park without the key in the ignition. } \\ \text { The recall involved } 2001 \text { to } 2002 \text { model-year } \\ \text { Dodge Dakota pickup trucks, Durango sports } \\ \text { utility vehicles, Ram van models, and 2002 } \\ \text { model-year Ram pickup trucks } \\ \text { GM announced a recall of } 857,735 \text { vehicles } \\ \text { equipped with a heated windshield wiper } \\ \text { fluid system for a potential short-circuit problem, } \\ \text { according to federal safety regulators } \\ \text { Ford completed a series of recalls affecting } \\ \text { 14 million vehicles due to faulty cruise control } \\ \text { deactivation switch. The latest recall involved } \\ \text { some 4.5 million vehicles } \\ \text { Honda recalled 646,000 of its Fit/Jazz and City } \\ \text { automobiles globally over a faulty window } \\ \text { switch after a child died when fire broke out in } \\ \text { a car last year. Honda made the announcement } \\ \text { as Toyota extended its own recall to China } \\ \text { and Europe }\end{array}$

Source: http://www.reuters.com/article/2010/02/10/toyota-recallsidUSSGE6190GC20100210?pageNumber=1 
Table 4 The 2005-2010 Toyota worldwide recalls

October 2005

September 26, 2007

November 2, 2009

November 26, 2009

January 21, 2010

January 27,2010

January 29, 2010

February 8, 2010

February 12, 2010

April 16, 2010

April 19, 2010

April 28, 2010

May 21, 2010

July 5,2010

July 29, 2010

August 28, 2010

February 8, 2011

February 22, 2011
World: Toyota recalled about 1.41 million cars globally, including the Corolla and 15 other models, due trouble with their headlight switching systems

USA: 55,000 Camry and ES 350 cars in "all-weather" floor mat recall

USA: 3.8 million Toyota and Lexus vehicles again recalled due to floor mat problem, this time for all driver's side mats

USA: floor mat recall amended to include brake override and increased to 4.2 million vehicles

USA: 2.3 million Toyota vehicles recalled due to faulty accelerator pedals (of those, 2.1 million already involved in floor mat recall)

USA: 1.1 million Toyotas added to amended floor mat recall

Europe, China: 1.8 million Toyotas added to faulty accelerator pedal recall

Worldwide: 436,000 hybrid vehicles in brake recall following 200 reports of Prius brake glitches

USA: 7,300 2010 Camry vehicles recalled over potential brake tube problems

USA: 8,000 MY 2010 4WD Tacoma pickup trucks recalled over concerns about possible defective front drive shafts

USA: 600,000 MY 1998-2010 Sienna minivans for possible corrosion of spare tire carrier cable

World: 21,000 MY 2010 Toyota Land Cruiser Prado and 13,000 Lexus GX 460 SUVs recalled to reprogram the stability control system

USA: 50,000 MY 2003 Toyota Sequoia recalled to reprogram the stability control system

Japan: 4,509; USA: 7,000 MY 2010 LS for steering system software update

World: 270,000 Crown and Lexus models for valve springs with potential production issue

USA: 412,000 Avalons and LX 470s for replacement of steering column components

USA and Canada: approximately 1.13 million Corolla and Corolla Matrix vehicles produced between 2005 and 2008 for engine control modules (ECM) that may have been improperly manufactured

USA: NASA and NHTSA inquiry reveals that there were no electronic faults in Toyota cars that would have caused acceleration issues. However, accelerator pedal entrapments remain a problem

Toyota recalls an additional 2.17 million vehicles for gas pedals that become trapped on floor hardware

Source: http://en.wikipedia.org/wiki/2009\%E2\%80\%932011_Toyota_vehicle_recalls

Table 5 The 2005-2010 auto industry mergers, partnerships, and bailouts

\begin{tabular}{|c|c|}
\hline May 2007 & DaimlerChrysler sells Chrysler Group to Cerberus Capital Management \\
\hline June 2008 & India's Tata Motors buys Jaguar and Land Rover from Ford \\
\hline December 2008 & $\begin{array}{l}\text { The US government approves the bailout plan, which would give loans of } \$ 17.4 \text { billion to US automakers GM and } \\
\text { Chrysler. \$13.4 billion is provided immediately, with another } \$ 4 \text { billion available in February } 2009 \text {. GM gets } \\
\$ 9.4 \text { billion and Chrysler gets } \$ 4 \text { billion }\end{array}$ \\
\hline April 2009 & Chrysler files for Chapter 11 bankruptcy \\
\hline June 2009 & $\begin{array}{l}\text { Chrysler emerges from a Chapter } 11 \text { reorganization and announces a plan for a partnership with Italian automaker Fiat. } \\
\text { Fiat holds a } 25 \% \text { stake in the new company, with an option to increase its stake to } 35 \% \text {, and up to } 51 \% \text {, if it meets } \\
\text { financial and developmental goals for the company. Fiat's stake cannot go beyond } 49 \% \text { until the government has } \\
\text { been paid back in full }\end{array}$ \\
\hline
\end{tabular}

Source: http://www.cbc.ca/news/canada/story/2008/10/22/f-automergers.html 


\section{Appendix 2-Measurement Items and Scale Definitions}

Table 6 Measurement Items and scale definitions

\section{Consistency}

$\mathrm{Con}=(\mathrm{x} 11+\mathrm{x} 12) / 2$

$\mathrm{x} 11=$ This brand's image in commercials and ads has been consistent for many years

$\mathrm{x} 12=$ the quality of this brand's automobiles has been consistent for many years

Brand investments

$\mathrm{BInv}=\mathrm{x} 13$

$\mathrm{x} 13=$ this brand spends a lot of money on ads, commercials, promotions, event sponsorships, celebrity endorsements, etc Clarity

$\mathrm{Cl}=(\mathrm{x} 14+\mathrm{x} 15+\mathrm{x} 16-\mathrm{x} 17) / 4$

$\mathrm{x} 14=$ this brands ads, prices, and vehicles match its overall image

$\mathrm{x} 15=\mathrm{I}$ know what this brand stands for

$\mathrm{x} 16=$ relative to other brands, this brand's claims are easier to understand

$\mathrm{x} 17=\mathrm{I}$ have trouble figuring out what image this brand is trying to create

Brand credibility

$\mathrm{BCr}=(\operatorname{Tr}+\mathrm{Ex})$

$\operatorname{Tr}=(\mathrm{x} 1+\mathrm{x} 2-\mathrm{x} 3+\mathrm{x} 4-\mathrm{x} 5+\mathrm{x} 6+\mathrm{x} 7) / 7$ [trustworthiness]

$\mathrm{x} 1=$ this brand delivers what it promises

$\mathrm{x} 2=$ this brand's product claims are believable

$\mathrm{x} 3=$ what is said in the ads for this brand is not very believable (-)

$\mathrm{x} 4=$ over time, my experiences with this brand have led me to expect it to keep its promises, no more and no less

$\mathrm{x} 5=$ my experiences with this brand make me wary of their claims $(-)$

$\mathrm{x} 6=$ this brand has a name you can trust

$\mathrm{x} 7=$ this brand does not pretend to be something it is not

$\mathrm{Ex}=(\mathrm{x} 8+\mathrm{x} 9+\mathrm{x} 10) / 3$ [expertise]

$\mathrm{X} 8=$ this brand is at the forefront of using technology to deliver a better automobile or service

$\mathrm{X} 9=$ this brand reminds me of someone who is competent and knows what he/she is doing

$\mathrm{x} 10=$ this brand has the ability to deliver what it promises

Relative price

$\mathrm{RPr}=\mathrm{x} 18$

$\mathrm{x} 18=$ this brand typically is higher priced compared to others

Perceived quality

$\mathrm{PQ}=(\mathrm{x} 19+\mathrm{x} 20) / 2$

$\mathrm{x} 19=$ the quality of this brand is very high

x $20=$ in terms of overall quality how would you rate these brands?

Purchase consideration

$\mathrm{PCon}=\mathrm{x} 21$

$\mathrm{x} 21=\mathrm{I}$ would seriously consider purchasing a vehicle from this brand

Warranty attractiveness

$\mathrm{GW}=\mathrm{x} 22$

$\mathrm{x} 22$ = producing automobiles backed by good warranties

Reliability

Rel $=x 23$ 
Table 6 (continued)

$\mathrm{x} 23=$ produces automobiles that have a reputation for being reliable

Service focus

Service $=\mathrm{x} 24$

$\times 24=$ servicing the customer is a big focus

Low operating costs

$\mathrm{LOC}=\mathrm{x} 25$

x25=making vehicles with low operating costs

Item coding

$\mathrm{x} 1-\mathrm{x} 19=-1$ if totally disagree $/=0$ if neither agree nor disagree $/=+1$ if totally agree

$\mathrm{x} 20=-1$ if low quality $/=0$ if average quality $/=+1$ if high quality

$\mathrm{x} 21=0$ if totally disagree or neither agree nor disagree/ +1 if totally agree

$\mathrm{x} 22-\mathrm{x} 25=-1$ if poor performance $/=0$ if mediocre performance $/=+1$ if performs very well

\section{References}

1. Aaker DA (1991) Managing brand equity. The Free Press, New York

2. Ahluwalia R, Burnkrant RE, Unnava HR (2000) Consumer response to negative publicity: the moderating role of commitment. J Mark Res 37(May):203-14

3. Bentler PM, Bonett D (1980) Significance tests and goodness of Fit in the analysis of covariance structures. Psychol Bull 88(3): 588-606

4. Cleeren K, Dekimpe MG, Kristiaan H (2008) Weathering productharm crisis. J Acad Mark Sci 36:262-70

5. Chen Y, Shankar G, Yong L (2009) Does a Firm's product-recall strategy affect its financial value? An examination of strategic alternatives during product-harm. J Mark 73:214-226

6. CNNMoney (2011a), "Toyota: one year later-buy a Toyota? Wouldn't think of it," Cable News Network, Time Warner Company, http://money.cnn.com/galleries/2011/autos/1101/gallery. toyota one year later/3.html

7. CNNMoney (2011b), "Toyota: one year later - the only loser," Cable News Network, Time Warner Company, http://money.cnn.com/ galleries/2011/autos/1101/gallery.toyota_one_year_later/index.html

8. Dawar, Niray and Madan M. Pillutla (2000), "Impact of productharm crises on brand equity: the moderating role of consumer expectations," Journal of Marketing Research, May, 215-26

9. Economist (2010a) "Getting the cow out of the ditch: Toyota's woes highlight the question of how to manage a product recall — and how not to," The Economist, http://www.economist.com/node/15496136? story id=E1 TVQJGTPG.

10. Economist (2010b) "Epiphany in Dearborn: how ford turned a crash into a profit - without a government bail-out," The Economist, http:// www.economist.com/node/17673258?story id=17673258.
11. Erdem T, Keane M, Sun B (2008) A dynamic model of brand choice when price and advertising signal product quality. Mark Sci 27(6): $1111-1125$

12. Erdem T, Swait J (1998) Brand equity as a signaling phenomenon. J Consum Psychol 7(April):131-157

13. Erdem T, Swait J (2004) Brand credibility, brand consideration and choice. J Consum Res 31(June):191-198

14. Erdem T, Joffre S, Jordan L (2002) The impact of brand credibility on consumer price sensitivity. Int J Res Mark 19(1):1-19

15. Erdem T, Joffre $S$ (2004) Brand credibility and its role in brand choice and consideration. J Consum Res 31(1):191-199

16. Keller KL (1993) Conceptualizing, measuring, and managing consumer-based brand equity. J Mark 57:1-22

17. Keller, Kevin. L. (2002), Strategic brand management: building, measuring and managing brand equity (2nd edn.) Upper Saddle River: Prentice Hall.

18. Langlois, Shawn (2010) "Toyota's U.S. market share breaks down in February,” MarketWatch, Marketwatch Inc., http://www.marketwatch. com/story/toyotas-us-market-share-breaks-down-2010-02-26.

19. Loomis Group (2010), "Brands in crisis: what is next for Toyota?" http://blog.loomisgroup.com/brands-in-crisis-whats-next-for-toyota

20. Roehm ML, Tybout AM (2007) When will a brand scandal spill over, and how should competitors respond? J Consum Res 43(3):366-73

21. Heerde V, Harald KH, Dekimpe MG (2007) The impact of a productharm crisis on marketing effectiveness. Mark Sci 26(2):230-45

22. Swait J, Erdem T (2007) Characterizing brand effects on choice Set formation and preference discrimination under uncertainty. Mark Sci 26(5):679-697

23. Telegraph (2011), "Toyota recall crisis is threat to the whole car industry," The Telegraph, http://www.telegraph.co.uk/finance/ newsbysector/industry/7191137/Toyota-recall-crisis-is-threat-towhole-car-industry.html 